\title{
Cigarette smuggling in Europe: who really benefits?
}

\author{
Luk Joossens, Martin Raw
}

\begin{abstract}
Cigarette smuggling, now on the increase, is so widespread and well organised that it poses a serious threat to public health. This threat comes from two principal directions. First, smuggling makes cigarettes available cheaply, thereby increasing consumption. A third of annual global exports go to the contraband market, representing an enormous impact on consumption, and thus causing an increase in the burden of disease, especially in poorer countries. It is also costing government treasuries thousands of millions of dollars in lost tax revenue. Second, the tobacco industry uses smuggling politically, lobbying governments to lower tax, arguing that smuggling is caused by price differences. This paper shows that the claimed correlation between high prices and high levels of smuggling does not exist in western Europe. In fact, countries such as Norway and Sweden, with expensive cigarettes, do not have a large smuggling problem, whereas countries in the south of Europe do. Cigarette smuggling is not caused principally by "market forces". It is mainly caused by fraud, by the illegal evasion of import duty. The cigarettes involved are not the cheap brands from southern European countries, for which there is no international market. It is the well-known international brands such as Marlboro and Winston. We propose much tighter regulation of cigarette trade, including an international transport convention, and a total ban on transit trade-sale by the manufacturers to dealers, who sell on to smugglers.
\end{abstract}

International Union Against Cancer, EU Liaison Office, Rue de Pascale 33, 1040 Brussels, Belgium

L Joossens

Department of Public Health and Epidemiology, Kings College School of Medicine and Dentistry, London, UK M Raw

Correspondence to: Dr L Joossens. joosens@globalink.org public health, and to government treasuries, which it is costing thousands of millions of dollars in lost tax revenue. Furthermore it is on the increase. The threat to public health comes from two principal directions. First, smuggling makes cigarettes available cheaply, thereby increasing consumption. Because, as we show, a third of annual global exports go to the contraband market, this effect is enormous. It causes a massive increase in the burden of disease, especially in poorer countries. Second, the tobacco industry uses smuggling politically to argue against high tobacco taxes. They did so successfully in Canada with a resulting increase in consumption and loss of revenue. ${ }^{2}$

Smuggling is also important because it tells us a lot about the true nature of the tobacco industry. We examine some industry arguments about the causes and nature of smuggling and find them to be less than convincing. Indeed, the evidence suggests that the tobacco manufacturers are the chief beneficiaries of smuggling, and as the above quotation from a tobacco trade report shows, they benefit from the way smuggling acts as a market entry strategy.

How big is the problem?

Almost a third of global cigarette exports is funnelled into the illegal contraband market. This figure is estimated by looking at the difference between global exports and imports, almost all of the "missing" cigarettes being smuggled.

World cigarette production is known fairly accurately, and because cigarettes do not keep for very long, world production is very close to world consumption (large quantities are not kept in storage). Thus global imports should be close to global exports after allowing for legitimate trade usually excluded from national statistics (principally imports for duty-free sales to travellers, the diplomatic community, and military establishments). Neither can the time lag of three to six months between recording export and import statistics explain export/import differences. ${ }^{2}$ Imports are lower than exports to a degree that cannot be explained by legitimate duty-free sales. Although the volume of duty-free trade is not on public record, it has been estimated by the tobacco trade at about 45000 million cigarettes a year. ${ }^{2}$ Of course legal imports could include cigarettes that are smuggled into a third country, so that even this estimate of smuggling could be an underestimate. 
Table 1 World cigarette imports and exports (thousands of millions of pieces)

\begin{tabular}{lclcl}
\hline & Exports & Imports & Difference & (\%) \\
\hline 1975 & 223 & 171 & 42 & 19 \\
1980 & 323 & 254 & 69 & 21 \\
1985 & 356 & 313 & 43 & 12 \\
1990 & 543 & 418 & 125 & 23 \\
1991 & 712 & 526 & 186 & 26 \\
1992 & 804 & 568 & 236 & 29 \\
1993 & 780 & 601 & 179 & 23 \\
1994 & 1156 & 886 & 270 & 23 \\
1995 & 987 & 668 & 319 & 32 \\
1996 & 1107 & 707 & 400 & 36 \\
\hline
\end{tabular}

The percentage given is the difference as a percentage of exports. Source of data: US Department of Agriculture. ${ }^{3}$

Table 1 shows annual global exports and imports from 1975 to 1996 . The figures are drawn from the Department of Agriculture in the United States, and are accepted as accurate and used by other American goverment agencies, for example, the Department of Health and Human Services. ${ }^{4}$ In 1996, 1107000 million cigarettes were exported but only 707000 million imported, a difference of 400000 million. After deducting 45000 million for legitimate duty-free sales, there are still about 355000 million cigarettes-32\% of global exports-missing. The European Union portion of this is about 60000 million pieces a year with an annual loss of revenue to European governments of $\$ 6000$ million a year. ${ }^{5}$ (All dollar prices are American unless otherwise stated.)

These figures are extraordinary. They mean that a third, perhaps more, of all exported cigarettes are illegally being sold cheaply. Given the relationship between price and consumption, this represents an enormous stimulus to consumption and thus to the burden of health problems for hard-pressed, cash-starved health services. Furthermore it is the poorer countries that bear the brunt of cigarette smuggling (see below).

\section{Why cigarettes?}

The attractiveness of cigarettes to the fraudster lies in the size of the difference between the duty-free and duty-paid price, which leaves room for substantial profit even at the relatively low street prices needed to attract consumers. They are also attractive because they are so easy to handle. Other highly taxed products, such as petroleum products, or even alcoholalso the object of fraud-cannot compete on a tax value per weight basis, or in terms of the conditions required for their transport. One "masterpack" of 10000 cigarettes is the size of a cardboard box common in supermarkets. A container load of these has a potential tax value of about $\$ 1200000$ (table 2), almost all of which is potential profit for the smuggler.

Large-scale smuggling also requires a willing market and a good local distribution network to supply it. Such markets and networks have existed for many years in Italy, where tobacco smuggling is long established and culturally accepted, and in Spain, where smuggling is also well established. The recent expansion in cigarette smuggling has therefore exploited these countries as a base for its infiltration of markets in the rest of the European Union, although the opening of central and eastern Europe has also provided new opportunities for the smugglers. ${ }^{5}$

\section{Causes of cigarette smuggling}

The tobacco industry argues that smuggling is caused by large price differences between cigarettes in different countries (we would call this a "market forces" argument) and that therefore the solution is to reduce tax. Given the high rate of taxation on cigarettes in many countries, and the price differences created by this, the argument sounds superficially attractive, even logical. If it were true, however, countries with highly priced cigarettes would experience high levels of smuggling into them, whereas countries where cigarettes are cheap would not. In fact almost the opposite is true.

Using data on nine countries from the European Confederation of Cigarette Retailers ${ }^{5}$ and other sources, ${ }^{67}$ we have classified the 15 European Union countries as high-smuggling countries, with a contraband market share of $10 \%$ or more (Spain $15 \%$, Austria $15 \%$, Italy $11.5 \%$, Germany 10\%), medium-smuggling countries, with a contraband market share between $5 \%$ and $10 \%$ (Netherlands $5-10 \%$, Belgium $7 \%$, Greece $8 \%$, and probably Luxembourg and Portugal, but no studies are available), and low-smuggling countries, with a contraband market share of less than 5\% (France 2\%, United Kingdom 1.5\%, ${ }^{6}$ Ireland $4 \%$, Sweden $2 \%,{ }^{7}$ Norway $2 \%,{ }^{8}$ and probably Denmark and Finland, but no studies are available). The results can be seen in table 3 .

The correlation between high prices and high levels of smuggling claimed by the tobacco industry simply does not exist. In fact countries with very expensive cigarettes, such as Norway, Sweden, Denmark, and the United Kingdom, do not have a large smuggling problem. Table 3 shows high levels of cigarette smuggling in the south of Europe rather than the north. Why should this be?

Cigarette smuggling is not caused principally by market forces. It is caused by fraud - by the illegal evasion of import duty.

Table 3 Prices of cigarettes (in US\$) and level of smuggling into countries of the European Union

\begin{tabular}{lll}
\hline Country & Price & Level of smuggling \\
\hline Spain & 1.20 & high \\
Portugal & 1.75 & medium \\
Greece & 2.06 & medium \\
Italy & 2.07 & high \\
Luxembourg & 2.12 & medium \\
Netherlands & 2.43 & medium \\
Austria & 2.69 & high \\
Belgium & 2.95 & medium \\
Germany & 3.02 & high \\
France & 3.38 & low \\
Finland & 4.26 & low \\
Ireland & 4.27 & low \\
United Kingdom & 4.35 & low \\
Denmark & 4.55 & low \\
Sweden & 4.97 & low \\
Norway & 6.27 & low \\
\hline
\end{tabular}

Notes: The table shows the price (in US $\$$ at 1 June 1997) of 20 cigarettes from the most popular price category. Sources for prices are the Commission of the European Communities and the Norwegian Council on Tobacco and Health.

$\star$ Probably; details of how this index was constructed are given in the text. 
The cigarettes involved are not the cheap brands from southern European countries. There is no international market for such brands. Cigarette smuggling is of expensive international brands made by the multinational corporations-Marlboro, Camel, and Winston, for example. These international brands are imported to warehouses in northern Belgium (see below). No duty is paid on them because they are marked for export from the European Union (EU) to third countries, in north Africa for example. In theory they are only in transit through the EU. They are then transported across Europe where they "disappear" during the journey, ${ }^{9}$ making their way into the hands of smugglers, and thence onto the streets. By evading duty they can be sold for about a dollar a pack, considerably cheaper than the official legal price. ${ }^{2}$

\section{Who benefits most from cigarette smuggling?}

The multinational manufacturers sell their cigarettes to traders, who then sell them on. The manufacturers say that once they have sold them, they have no further legal responsibility for them, or knowledge of where they go. ${ }^{9}$ It is instructive then to consider who benefits most from this illegal evasion of duty.

The manufacturers gain their normal profit by selling the cigarettes (legally) to distributors. The cigarettes then find their way onto the black market to be sold at greatly reduced prices, stimulating demand. This puts pressure on governments not to increase tax because of the loss of revenue, which may also result in lower prices and higher consumption, as happened in Canada. Then the industry uses this to urge governments to reduce, or not to increase, taxes. Finally, contraband cigarettes that are intercepted by customs have then to be replaced-creating yet more sales. ${ }^{2}$ Thus the real beneficiaries of cigarette smuggling are the multinationals. For them smuggling equates to higher sales. In fact the benefits are even greater, as has been ackowledged by a tobacco trade report.

Smuggling as a market entry strategy The trade journal World Tobacco admitted in a 1996 report that "Although sales of contraband cigarettes have affected the level of income that governments world-wide derive from tobacco sales, smuggling has also helped to promote some of the world's leading brands in markets which had remained closed to foreign imports and where demand for Western cigarettes has continued to grow." Writing in Tobacco fournal International in 1993, Michael Barford stated: "Whose brands sell best in contraband trade? Traditional smuggling has focused on well-known international brands, since instant recognition and confidence in the merchandise are essential to these quick, furtive transactions. Smugglers are impatient of little-known brands. They focus on what the multinationals make." 10

Smuggling makes top international brands available at affordable prices to low-income consumers, and to image-conscious young people in developing countries where Western products are regarded as sophisticated and stylish. In other words, smuggling can be viewed as a market entry strategy. Some examples emphasise the point.

ARGENTINA

In the early 1960s there was a strong temporal relationship between the rise of smuggling and the entry of multinational tobacco companies into the Latin American market. In effect smuggling forced open the market, allowing entry to the multinationals. Contraband rose from $2 \%$ to $12 \%$ of total consumption until the nationally owned firms were acquired by the multinationals, whereupon it mysteriously declined in the early 1970 s. $^{4}$

ITALY

Italy has the longest history of smuggling in Europe. Cigarette production is controlled by a state monopoly, and cigarette advertising has been banned since 1963, theoretically making it difficult for foreign brands to compete. Yet Marlboro, by far the most smuggled brand in Italy, is also the market leader, with a share in 1996 of $50 \%$. Smuggled Marlboro are sold more cheaply than the leading national brand MS. ${ }^{11}$

\section{BULGARIA}

Bulgaria is one of the few countries in eastern Europe that still has a state-controlled tobacco industry, and it is also one of the poorest, with an average income in 1996 of $\$ 90$ a month. In 1995 the consumption of domestic cigarettes was estimated to be 13000 million cigarettes, with illegal imports estimated at about 5000 million, or $38 \%$ of total consumption. ${ }^{12}$ Here, as in many other countries, American cigarettes are popular among young people, but most cannot afford them at the official legal price. At 1997 prices a pack of Marlboro costs $\$ 3$ whereas a smuggled pack only costs $\$ 1$. At the official price the market for American cigarettes would have been extremely limited, whereas at the smuggled price it is huge.

CHINA

China is the biggest cigarette market in the world. It is a difficult market to penetrate and has an advertising ban; nevertheless it has been estimated that some 40000 million cigarettes are smuggled into China every year. ${ }^{13}$ The market is so huge it is difficult to imagine any industry not wanting to establish a foothold in it. The willingness of the multinational cigarette manufacturers to co-operate in stamping out smuggling of their brands into China would provide a litmus test of their good faith and abhorrence of illegality.

\section{Transit fraud}

Transit fraud is at the heart of cigarette smuggling in Europe. In 1997 a committee of the European Parliament published a detailed report on transit procedures in the European Union. ${ }^{5}$ A complex system of checks and documentation allows the temporary suspension of customs duties, excise, and value-added 


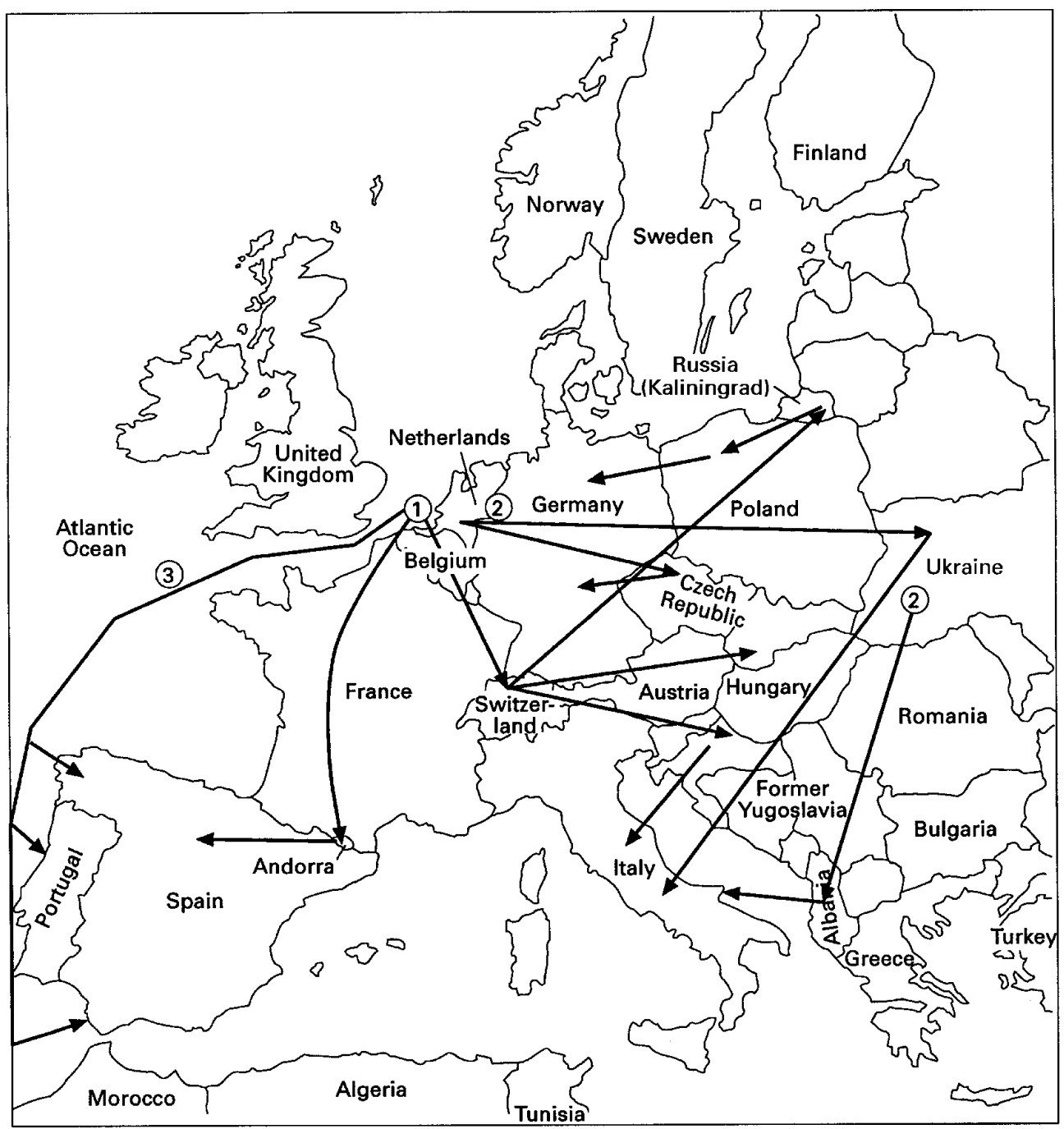

Table 4 American cigarette exports to Belgium (thousands of millions of pieces)

\begin{tabular}{ll}
\hline Year & Exports \\
\hline 1986 & 17.5 \\
1987 & 23.0 \\
1988 & 26.7 \\
1989 & 33.7 \\
1990 & 53.5 \\
1991 & 48.2 \\
1992 & 53.3 \\
1993 & 51.2 \\
1994 & 71.8 \\
1995 & 71.4 \\
1996 & 61.8 \\
\hline
\end{tabular}

Source: US Department of Agriculture.

Table 5 Cigarette exports from Brazil (thousands of millions of pieces)

\begin{tabular}{ll}
\hline Year & Exports \\
\hline 1990 & 10 \\
1991 & 20 \\
1992 & 25 \\
1993 & 30 \\
1994 & 55 \\
1995 & 55 \\
1996 & $78^{\star}$
\end{tabular}

*Of which 38 thousand million went to Belgium. Source: US Department of Agriculture.

Smuggling routes—see text for description.

tax payable on goods originating from a third country, or destined for it, while they are transported through Europe. For example, cigarettes from the United States enter Antwerp for onward transport to north Africa. They enter this transit system for transport by road from Antwerp to Spain, from where they would be shipped to north Africa. Provided their export is confirmed, no taxes are due in the European Union. Fraud occurs when these duty-free goods are sold on the black market. The European parliamentary committee has revealed the complexity of the routes by which contraband cigarettes now enter free circulation in the Union.

The port of Antwerp in Belgium provides cigarette warehousing facilities unparalleled elsewhere in Europe. In 1996 about 100000 million cigarettes passed through the port-62 000 million were imported from the United States (mainly from Philip Morris and RJ Reynolds) and 38000 million from Brazil (from factories owned by Philip Morris and BAT) (see tables 4 and 5).

Aside from the relatively small proportion intended for duty-free sales, none of these cigarettes are destined for the EU market, because the large American producers supply their legitimate EU markets entirely out of EU production facilities. These cigarettes are for export to third countries. Thus anyone wishing to purchase American duty-free cigarettes for European black markets is likely to buy products warehoused in Antwerp, simply because that is where the cigarettes are. The estimated total value of 100000 million tax-free cigarettes in transit is $\$ 14000$ million. It is these transit cigarettes that end up being sold illegally in Europe with, according to a recent New York Times article, ${ }^{5}$ remarkable ease and lack of control.

\section{Smuggling routes}

Two major trade routes involve the transport of cigarettes into eastern Europe and the former Soviet Union. They are first transferred by road from Belgium to a free zone in Switzerland, at which point they are outside EU law, and they then leave Switzerland under new transit regulations for destinations in central and eastern Europe or one of the former Soviet republics (route 1 in the figure).

On another route (route 2 on the map), cigarettes are taken from port warehouses to regional airports in Belgium or the Netherlands, flown (up to five container loads 
per aircraft) to destinations in eastern Europe, from where they return to the EU in a number of ways, especially to Italy and Germany. In Germany the process has been described as "ant-smuggling" (Ameisenschmuggel) - the clandestine transport of cigarettes across the eastern border in a vast number of small consignments carried in private cars and small vans. These cigarettes supply the Italian market as well as those in other EU countries.

For Italy cigarettes are transported in vast quantities from Albania and the republics of the former Yugoslavia across the Adriatic in fast boats and landed on the long coastline, a traditional and long-established route.

In our final example (route 3 on the map), to some extent replacing traditional routes through Gibraltar and Andorra, cigarettes are taken by sea from northern European ports. Documents are prepared indicating final destinations in north Africa, but the sea route passes close to Spanish territorial waters, where they are offloaded and landed by fast boats on the Spanish coast. ${ }^{59}$

The structure of the transactions is kept as complex as possible to make investigation as difficult as possible. A consignment of cigarettes will pass through a bewildering range of owners in a short space of time before reaching the final owner, and the links between successive owners are as obscure as possible. In one example, ${ }^{9}$ a consignment of American cigarettes was sold by the Swiss subsidiary of an American multinational to a company owned by a Swiss trader, who sold them on to a Panamanian company, which labelled them as destined for Senegal in west Africa. This particular consignment was intercepted by Spanish police off the Spanish coast, where they would have been landed by speedboat.

\section{Attitude of the multinationals}

The line of the multinationals is that they sell their cigarettes legally to dealers and that their responsibility ends there. Some dealers themselves have accused the industry of lying when they say they have no knowledge of where their cigarettes are going. Given the sheer scale of smuggling, shown by the gap between exports and imports, it would be odd indeed if the industry had no idea what was going on. It would be like the British admiral Lord Nelson at the battle of Copenhagen in 1801, putting his telescope to his blind eye and declaring "I really do not see the signal".

And the attitude of the industry? Much European tobacco trade is done in Switzerland which, with Antwerp, could be thought of as a hub of the trade. Philip Morris and RJ Reynolds have their European headquarters there. According to a New York Times article ${ }^{9}$ when EU investigators questioned RJ Reynolds officials, they declined to help on the grounds that Swiss commercial secrecy laws prevented them. And in the United States a former Brown \& Williamson executive pleaded guilty to trafficking in contraband cigarettes. The cigarettes were sent from a warehouse in Alabama to a private warehouse in Louisiana, were marked for offshore vessels and thus were tax free, and were then sold to a Vietnamese organisation that smuggled them into Canada. ${ }^{14}$

\section{Discussion and recommendations}

The scale of cigarette smuggling represents a huge threat to public health by stimulating consumption, while at the same time depriving government of thousands of millions of dollars in tax revenue. It is also increasing, indicating the extreme difficulty of controlling it. The tobacco industry's assertion that smuggling is caused by high taxation and its attendant price differences is at best only occasionally true. And strong circumstantial evidence calls into question their sincerity in expressing concern about cigarette smuggling. They are often the main beneficiaries of it. We believe that cigarette smuggling can be reduced but that action will have to be international and include measures to simplify trade routes, with or without the industry's co-operation. We offer the following recommendations.

PENALTIES FOR TOBACCO SMUGGLING SHOULD BE REVISED

Many of the penalties for tobacco smuggling are out of date. They should be stiffened as part of revision of laws on tobacco taxation. The key to such revision is to ensure that the penalties for smuggling, when combined with the probability of getting caught, render tobacco smuggling financially unappealing. These penalties should not only target the import/export companies and intermediaries; they should target the multinational manufacturers, who should be made responsible for the destination of their products (see below).

ALL TOBACCO PRODUCTS SHOULD PROMINENTLY DISPLAY TAX STAMPS SHOWING THAT APPLICABLE TAXES HAVE BEEN PAID

This has been done in various ways in different countries. The purpose is to clearly distinguish between legal and illegal goods, making contraband products easier to detect and the laws easier to enforce. Many European countries already require "tax-paid" stamps to be affixed to cigarette packets under the cellophane wrapping.

RECORD-KEEPING REQUIREMENTS FOR REVENUE PURPOSES SHOULD BE INCREASED

The record-keeping and reporting requirements for revenue purposes are full of loopholes. They should be improved as part of the revision of laws on tobacco taxation. The present system allows multinational corporations to sell cigarettes legally to intermediaries, and thereafter escape all responsibility for what happens to the cigarettes. Record-keeping and tracking systems are needed which place the onus on the manufacturers to prove the cigarettes arrive legally in their end-user markets.

CIGARETTE PACKAGING SHOULD CARRY CLEAR LABELLING THAT MAKES IT EASY TO TRACK THEM FROM MANUFACTURER TO END-USER MARKET Such a measure would complement the previous two recommendations and should be part of an international convention on tobacco transport (see below). 
SALES SHOULD BE RESTRICTED

Clamping down on the outlets for smuggled cigarettes, which in some countries are almost part of the culture, would require not only law enforcement, but a change in smokers' attitudes toward authority. Sales should be restricted to licensed premises, with heavy fines for sales through unlicensed premises and vendors. In the Czech Republic, punishing the sale of cigarettes without tax stamps by a heavy fine has had a measurable impact (personal communication with A Sir, National Centre for Health Promotion, Prague, Czech Republic, 28 October 1995).

SUPPLY SHOULD BE CONTROLLED AND TRANSIT TRADE SHOULD BE OUTLAWED

Finally, and probably most important, is the reduction of supply. This will require greater co-operation between customs officials and other organisations. As with illegal drugs (which, from the control point of view, nicotine seems increasingly to resemble) we believe it is time for an international convention controlling the transport of cigarettes. In view of the involvement of organised crime, this convention would need the support of governments throughout the world as well as of some central organisation. $^{2}$

The World Health Organisation is seeking to address these international issues through an international framework for tobacco control. ${ }^{7}$ We welcome this initiative and urge the adoption of an international convention that would strictly control the transport of cigarettes internationally. The transit trade of cigarettes should be outlawed altogether. It is absurd that cigarettes might, for example, be transported from a warehouse in the United States to a warehouse in Antwerp, sold by the subsidiary of the American company to a Swiss company, which sells them on to a Panamanian company, which ships them by sea to north Africa, except that they actually end up in
Spain. There is no reason-if this were legitimate trade and the cigarette manufacturer were acting with good faith-why the manufacturer should not ship the cigarettes direct to north Africa.

That is what should happen: cigarette manufacturers should not be allowed to sell to intermediaries. They should be obliged to export directly to importing countries and, like the arms trade, produce end-user certificates, and proofs of purchase, tax payment, and import. The convention should stipulate that the transport of cigarettes would only be allowed if there is an agreement on the final destination, and that the cigarettes have adequate and country-specific health warnings and tax stamps.

LJ would like to acknowledge financial support from the UICC.

1 World Tobacco. World Tobacco file 1996. London: World Tobacco, 1996.

2 Joossens L, Raw M. Smuggling and cross border shopping of tobacco in Europe. BMF 1995;310:1393-7.

3 US Department of Agriculture. Tobacco: world markets and trade. Foreign Agricultural Service, Circular Series, August 1997.

4 US Department of Health and Human Services. Smoking and health in the Americas: a 1992 report of the Surgeon General in collaboration with the Pan American Health Organization. Atlanta, Georgia: Centers for Disease Control, Office tion. Atlanta, Georgia: Centers for Disease Control, Office
on Smoking and Health, 1992. (DHHS Publication No (CDC) 92-8419.)

5 Anon. Committee of inquiry into the community transit system. Brussels: European Parliament, 1997 (4 volumes).

6 Her Majesty's Treasury. Parliamentary answer to Dawn Primarolo, 1 July 1997.

7 Persson LGW, Andersson J. Cigarette-smuggling. Stockholm: Swedish National Police College, 1997.

8 Lund KE. A note on the changes in tobacco use since 1970. Oslo, Norway: National Council on Tobacco and Health, 1990. (NCTH document 36/1990.)

9 Bonner R, Drew C. Cigarette makers are seen as aiding rise in smuggling. New York Times 1997 Aug 25.

10 Barford MF. New dimensions boost cigarette smuggling. Tobacco f Int 1993;3:16-18.

11 Bonner R. Two cases shed light on cigarette smuggling in Italy. New York Times 1997 Sep 2.

12 US Department of Agriculture. Unofficial report on tobacco from Bulgaria (not official USDA data), 1 May 1997.

3 Yuan HA. Cigarette production down; contraband \& counterfeits flourish. Tobacco Reporter 1997;4:32.

14 Former B\&W executive convicted of cigarette smuggling. Associated Press, 16 October 1997. 